\title{
"It Is a Calling to be Part of Forming Children's Lives": Insights for Developing an Educational Curriculum for Early Childhood Educators' as a Second Career
}

\author{
Shoshana Veitzman, Mira Karnieli \\ Faculty of Education, Oranim College of Education \\ Kiriat Tivon, Israel
}

\begin{abstract}
Mobility between jobs, changing profession and professional identity are currently common. Using the qualitative-phenomenological paradigm, this study examined the underlining motives of female academics who chose early childhood education as their second career. We further examined the suitability and appropriateness of our teachers' college training programs toward this student population.

Electing early childhood teaching as second career required the students to re-evaluate their professional future, by listening to their inner voice, their personal-professional aspirations, sense of purpose and commitment, which are beyond oneself and reward. While the students bring with them a wealth of experience and extensive knowledge from their current field of expertise they were unable to identify the advantages of these prior experiences as potential empowering factors that could be implemented within their new profession. Further, most of the students expected practical apprenticeship learning rather than theoretical expansion as a basis for specialization. Studenteducators should assist these students utilization of their prior experience as potential empowerment factors that can be implemented within their new profession. Further, the programs should be modified for this population, addressing their expectations concomitantly focusing on theoretical genres derived from daily issues of kindergarten routine. Thus, enrich the education system with quality professionals.
\end{abstract}

\section{Introduction}

The current era is characterized by rapid changes, accessible information, improved quality of life, and longer life expectancy. The dynamic and rapid changes in work environment from stable long-term jobs to employment flexibility set the ground for optional job mobility, like developing a second career in teaching. Electing teaching as a second career relates to acquiring new skills and a new professional identity, sense of social mission and occurs due to intrinsic and extrinsic motivations [1],
[2]. However, these trends and new type of students create new challenges to the traditional curriculum for student educators, requiring a somewhat different and personalized tailored curriculum. Such a curriculum is not yet clearly established. Facing this challenge, and in an attempt for a deeper understanding of the actual needs of these students, the present study describes the background, motivations and perceptions of thirty-four female students choosing a second career as preschool teachers within a college of education in Israel. This exploration and the insight that followed assisted us in suggesting specific guidelines for a tailored curriculum for such and similar groups.

In the past the norm and traditional views led to perceiving a career as a longitudinal developmental sequence characterized by an individual's desire to hold a job and advance within it. Nowadays the spiral approach is more common, meaning progressively broadening one's knowledge and skills over time. Following this trend in recent years, it became more common that after an individual made a choice to start his or her career in a particular field, s/he may decide to make a periodic move into new fields and types of work [3]. In these cases, usually people follow their sense of purpose or vocation and are attentive to their inner voice calling that leads to change [4]. The desire for security, quality time with family and sense of purpose, seem to be among the most significant factors in the decision to leave a job and a steady income and become teachers [5], thus going through a change.

A process of change, according to the theory of transition, rests on four interrelated elements, which influence the process: the context of change; the support system received during the transition; the strategies that one uses to make the change; and personal characteristics and motivation [6]. During this change and transition period, the vulnerability of the individual is elevated. Arthur [7] described this change within the career using the term "boundary less careers". Boundary less careers supposedly offer higher levels of personal satisfaction, opportunities for growth and greater autonomy [8]. To deal with this change, elevated vulnerability and wish to make this a purposeful and positive experience the authors 
emphasize the importance of recognizing the experience gained in their former careers and identifying the skills acquired earlier in different situations and places and finding the way to apply these in their new career [9].

Despite growing numbers of professionals who switch to a second career in teaching [10], there are only a few studies on training for preschool teachers as a second career [11]. Understanding the specific needs and their own capabilities brought to early childhood teacher education profession is critical to help student educators' facilitate these students' professional identity development into their new careers and base these on their needs as well as their former experience and expertise.

As a result of the increasing demand for teaching as a second career, education colleges have established teacher training programs for these academics. Establishing the program at our college was based on ideas and theories embedded in adult education (andragogy) 1 [12], perceptions that the learning process is a continuous one (life-long learning) [13] and the need to tailor the program to second career specifics and personal needs. In practice, the described curriculum in this manuscript was derived from existing college undergraduate training programs, with specific adjustment and tailoring for this population's specific requirements.

\section{Research methods}

The purpose of this study was to construct a personalized training curriculum for training second career students in early childhood teaching. Accordingly, we used the qualitativephenomenological paradigm with the intent of a profound understanding of the interviewee's own idiosyncratic perception of motivations, processes and connotations that led them to choose teaching preschoolers [14, 15].

To acquire in depth data, the 34 students participating in the program were interviewed and asked to answer several open ended questions regarding their previous work experiences and perceptions. For examples, we asked why and what initiated their decision of a career change? What is the significance attributed to this choice? What are their expectations of the training program? Can they point out the skills and abilities acquired in their past? Are they able to recognize the added value and potential of applying these skills in their new career; and how to use these skills for their training and teaching process empowerment? In addition, we conducted semi-structured in-depth interviews with six students selected randomly [16], as well as with the didactic coordinator and head of the program.

The information gathered by these tools helped us determine and characterize the similarities and differences among the students' perceptions, their background, motivations and processes involved in choosing teaching as a second career [17].

The present study is an ethnographic phenomenological qualitative study focused on the candidates' past work experience, view of the motives and actions, processes, intentions and insights experienced through the transition process of moving toward a second career as teachers. The phenomenological study's assumption is that the knowledge is buried/cached in the significance the participants give to their actions. Learning takes place via the descriptions of their experience (What) and the manner in which the process evolved (How) as well as the significance attributed by the participants. According to this approach, the theory is built inductively during the research from the reality in the field studied [18], [19]. The basis of the study was triangulation of various information sources as a means to uphold the study's quality [18]. The analysis was based on organizing the data into unified categories, while providing interpretations and explanations based on the findings and the literature [20]. The categories were then raised to a higher level of abstraction, and became the basis for theory development [19]. The data analysis process was based on transparency in the conduct of research in general and in all stages of analysis in particular, thus each investigator was able to judge and evaluate the research process [21].

It was imperative to address ethical issues during the study: prior to each interview, the participant signed an informed consent; we made sure that they understood in advance the purpose of the study and gave their consent to participate voluntarily. We were careful not to use manipulation to achieve cooperation or receive information that they did not wish to give. Further in order to protect the anonymity of the speakers while quoting their words, in this manuscript we use the first letter of their name as an identifier. In addition, the students gave us prior written consent to publish the study.

The research was conducted at the same college where the authors are staff members. None of us teaches them directly. One is the academic coordinator of the teacher-training program. The interviews were led by the researcher, which is not associated with the program.

\section{Findings}

Generally, we found that the decision to make a career change required a re-evaluation of their future, financial investment, taking the time to adjust and modify their daily routine. The decision also had economic (loss of income) and social consequences (professional status decline and the negative attitudes by associates) as described below.

First, we examined the academic and professional background of the subjects. 


\subsection{First career}

A. Is a certified public accountant (CPA). According to her, choosing the CPA profession was derived from her parents' wishes, the status associated with being a CPA with high income. She did not invest in thinking about the nature of the profession, and its demands:

When I chose to study accounting and economics I did not think, parental guidance, sitting with friends, I like money and efficiency and it seemed great. I started studying, I barely came to classes, received a license, worked in the profession and was not interested, I was bored.

In retrospect, she recognizes the signs, which pointed to a lack of interest in her chosen profession during her studies:

If something was not interesting I'd take off, I felt sick. During my studies I was concerned I was not in the right place but I gave it a chance and I did not contemplate much, I just did not give it a thought. All those surroundings me chose sciences as professions, and I was sure it would work for me. After four years of intensive studies and another, nearly four years of work in an accounting firm, I realized that the profession does not interest me. I felt frustration, lack of challenge and dissatisfaction. Sitting at the computer in the office all day and the occupation in such a dull field were not for me.

Even when she decided to quit her profession, she did not decide on what profession she will choose:

After two successive maternity leaves, I did not want to return to the profession. However, I never thought about working with children as a career. I realized I needed to make a change! I thought and picked my brain about what I like, what interests me and what I feel I would be one of the best in the field.

A.'s words describe stages of development over time and maturity, particularly from young professionals who make choices for extrinsic reasons, to a position where she identifies her needs and desires and dares "to follow my heart".

Like A. N., an economist by training, recognized that the profession she chose does not satisfy her:

After six years of working in banking and insurance, I realized it was not my field.

Similar to A. H. consulted with her mother when choosing her first profession, without examining the essence of the profession. She also felt a lack of interest in the course of her studies, but unlike A., she has already identified during her studies the desire to engage in early childhood teaching. Right after finishing her undergraduate studies, she quickly made the change:

I sat with my mother and thought about what to study. I chose economics, it did not interest me, and I wanted people and transferred to Human Services. During my studies, I felt I related to working with people and especially children. Possibly, if I would have waited a little, I would have switched to education immediately.

E. studied business administration, chosen according to her, as a profession, which provides status and a high income, components she did not think she would find in education, but practically she worked with children:

I decided to study business administration because I thought that I had to work at a serious job, one that would make me money and a lot. I did not believe that in education I could get there. I also hoped to work convenient hours and not around-the-clock. As time passed, I found that I increasingly engaged in working with children.

An underlining statement was common throughout the interviews and questionnaires. Deciding about the first profession or carrier was not the subjectpreferred choice of most of them. The decision was affected by the need to please their parents, the desire to obtain important socio-professional status with high income. However, their inner voice, heartfelt desires, and their intrinsic personal needs seem to be somehow silenced.

Further, they did not truly understand the nature of the chosen first profession. For example, S. an interior designer refers to an unsuitable curriculum during her studies as a factor that distanced her from her profession. Upon graduation, she felt a lack of practical knowledge and skills to work as an interior designer. This seems to be her turning point toward changing her profession.

My dream was to be an interior designer. I learned interior design for four years. These were academic studies using a research approach, with no association to the actual work. They gave us tools for diverse thinking which was investigative and creative. I can analyze from different directions, but there is no relation to practical work. After graduation, I decided I did not want to be an interior designer. I felt saturated and intense pressure. Now education beckons me. 
Other examples show two subjects which according to them, were drawn to working with children and one even worked with toddlers in her youth. But despite their interest in education, they chose first other professions. However, they were unable to explain the disparity between their first carrier choice and their inclination:

From an early age, I dreamed of working with children. At the end of my studies at school, I worked in a preschool and infant class. I really liked what I did, on my way to work I smiled to myself because I knew the kids liked me and were waiting for me. After graduating, I worked in various occupations. Finally, I got lucky and started working as an assistant at daycare and kindergarten classes. I am pleased I got to work with children but feel the need to advance professionally. I want to be a good teacher, to acquire knowledge and values.

Everyone knew that I love children and get along with them very well. I saw this as a personality trait until I realized that it could be utilized as an occupation for life. And here I am very happy!

T. studied art and by coincidence was assigned to preschool as teacher assistant. This experience revealed her professional vocation:

I got to the role of kindergarten teacher by chance. The woman who later became my boss asked me to replace her kindergarten teacher. I fell in love with the work and concluded that this was what I should do with my life, I'm here to professionalize.

Another student graduated history of Israel and Bible studies along with teaching certificate for High School. While being in the education field, she felt dissatisfied teaching high school:

I taught high school students for 12 years and then I chose to reach early childhood teaching.

Thirty of the Thirty-four students interviewed mentioned that their first profession selection was made without sufficient in depth consideration. Conduct analysis in accordance with the epistemological approach suggest that choosing second career as early childhood educator resulted mainly to the ability to identify the personal needs and inclinations and courageously follow them. Similar conclusions were previously described.

\subsection{Vocation}

According to the students the choice of profession as "early childhood educator", was mainly due to an inner need of accomplishment, a sense of purpose and a belief in their ability to contribute to the education and influence of children, as they put it: "heart's command". One can describe it as a vocation (a sense of equivalence and being valuable that requires deep commitment with strong feeling of suitability for a particular career or occupation $[3,4]$.

A.: I realized that my heart knows better than my mind what is good for me and what I was meant for in life. I went through a reflective process in which I concluded that what I love most are children. It is fun for me to talk to them, find out about their world, to laugh with them and make them laugh. Work as a kindergarten teacher requires a great soul and I feel I can give mine to our future generation and to influence them. Although a teacher's career is viewed as not important enough, in my opinion kindergarten teaching is one of the most moving, satisfying, fun, fulfilling and honest occupations and this time I went with my heart.

Student: It is a calling to be part of forming children's lives. The children are like clay, it's magical. I have an internal love for children, able to converse with them, and gain their trust. Working with preschoolers there bears an immediate reword from them, from their parents, and the surroundings that I really like.

E.: My inner voice is calling me. My friends said I should go to graduate school and that choosing to become a kindergarten teacher is kind of regression. A career for me is something internal, something you're good at and can make a contribution and uphold. I could not see myself sitting in the office for years, this does not satisfy me. I am sure that working in the kindergarten will fill me with joy. This year for me is a dream! Every day I am falling in love with what I do and what I am learning.

Student: I see myself getting up and going to work happy and doing what is right for me.

$E$. the pedagogic coordinator, supports the students' statements, and emphasizes that the current decision was wisely taken this time:

The students' desire to be kindergarten teachers is authentic, honest intention, passion, faith in the new profession in working with children.

The decision to change professional career is complex, requiring observation "inwardly" honesty and courage, taking into account individual needs and having the ability to face the consequences. According to their answers selecting early childhood 
education, gives them a sense of self-worth, being meaningful to children's education, along with a sense of joy and satisfaction. Observing their conversations, speech mode and body language, it is apparent that the students feel joy and enthusiasm about their studies. Similar expressions were mentioned in the questionnaires: "I followed my inner voice", "My heart knows better than my mind" and more. These quotes support the conclusion that choosing early childhood teaching, was subsequent to an inner need for meaningful work concomitant with sense of mission.

\subsection{Supporting figures in choosing the profession}

Transforming from familiar profession to a new one involves economic setback and even criticism of the surrounding family members and friends, especially when the new profession is perceived as less prestigious with a relatively low income. Perhaps that is why the students underlined the fact that in order to make this career change, they substantially relied on the support of a close person as described below.

A: I had to go through a process of deciding to be a teacher, a profession that is not perceived as prestige and appreciated. Thanks to my mother in-law who helped and encouraged me along with my love for children, I realized that I had to learn a profession that involved children. Nevertheless, telling my parents and my surroundings was very difficult. I actually almost did not tell anyone, but that's what I decided to do. It's me! This is my field.

Q: I had a stigma on the profession that has changed thanks to my sister-in-law who is a kindergarten teacher.

H: My brother's girlfriend is a kindergarten teacher and she stirred my interest in the profession, the same with my aunt. It was my mother who influenced me to be a kindergarten teacher; she was the most significant figure. Now I'm here and I'm very pleased. Society sees it as regression in our competitive world, where people seek status, career and money, but it does not bother me.

The encouragement, support, and guidance of someone close and meaningful are important anchors in implementing the choice, and facilitate the inner debate between the desire for selffulfillment, as opposed to social and economic concepts that communicate the necessity for status and prestige

\subsection{Motherhood}

All students noted that the transformation to motherhood played a significant role and was a turning point in their decision to choose the second careers as kindergarten teacher:

The turning point came when I became a mother, and I did not consider that the statement, "Today's children are tomorrow's future" is trite and corny.

Because I am a mother of three I have a strong connection with young children, and I think I have the skills and inclination to educate young children.

As a mother, I enjoy entering the kindergarten class in the mornings. Probably then I realized that in order to fulfill myself I had to study education.

The decision to have a second career as a kindergarten teacher, strengthened after the birth of my son when I decided I wanted to be an educator, really educated.

In seems that motherhood inspires the students to recognize the importance of preschool education, and as a result intensifies their sense of self-efficacy and capability to work in education.

\subsection{Added value}

To construct a significant training program for the students, we studied their ability to identify the skills and knowledge they bring with them from their previous work experience. Essentially, we inquired whether they can identify those skills and how to implement them in their new profession. Twenty-nine of the students had difficulties in identifying and applying the former skills and knowledge acquired in their previous profession towards the new one, as described in brief:

I have something from my former studies, which can contribute, but I do not know what.

The knowledge I came with is from raising my daughters.

My added value is age (30.5) and motherhood has an advantage.

I do not know if I bring something. My wisdom is in giving warmth and love.

I do not know how much of my work in customer service will contribute to work in education, but I 
have patience, the ability to listen and a desire to learn and improve.

They perceived that their advantage lay in their relatively mature age and their role as mothers. The Pedagogical coordinator also believes that the knowledge expressed at this point is "wisdom of maternal pedagogy".

Five candidates were able to identify the knowledge and experience gained as contributing skills towards the new profession:

I come from a spatial background [interior designer], and adjust the surroundings to people, I will use it in the kindergarten.

My previous knowledge and experience contribute to my sense of security. Good interpersonal skills, leadership, patience and responsibility, perseverance and determination, values and personal example.

As I previously worked as a clown, I guess that music, songs and dances will always be part of my daily routine in the kindergarten. I will address parents as customers I need to keep in touch with and get them interested.

My job was to preserve and nurture relationships with some of the larger firms in the country and abroad. I gave service and dealt with customer complaints. As a kindergarten teacher, I believe that the experience I gained will help me deal with the parents.

There is no doubt that my degree in art will contribute greatly to my work in the kindergarten. Creativity is a large part of the kindergarten, the subject tables, accessories, illustrations, and artwork.

The pedagogical coordinator identified and recognized the added value of experience within the students. Accordingly, she tried to make it accessible and valuable. She facilitated the process using guided questions in order to connect to the knowledge, skills and experience gained in the past to be embedded in each student. Thus, helping them to recognize the experience and knowledge gained as a resource for professional and personal empowerment and link to the new acquired profession and by learning from one another.

Indeed the students carry within themselves vast experience and knowledge, but encountered difficulty to apply it to the new profession. It seems that the "how" is more important to the students [rather than the substance "what"]. I took advantage of their knowledge to learn from each other and learn from the shared experience. For example, the interior designer has contributed greatly on how to organize and utilize natural light to avoid the use of fluorescent light: Northern window advantages compared to the use of air conditioner; a student who is an artist with an interest in ecological gardens introduced the work with mud to the kindergarten where she is an intern and contributed her knowledge to us.

The findings demonstrate that most of the students have major difficulty to identify their previously acquired skills and applying them toward the new profession. Thus, it remains the teacher educator's role to facilitate the difficult task for insight inquiries to identify their skills and applying it to new profession. Although their Pedagogical coordinator noticed these difficulties, the process is mostly intuitive, and is not embedded in the curriculum.

\subsection{Expectations from the studies}

We also examined what were the expectations of the students from the training program. The findings clearly indicate their need for strengthening and anchoring the theoretical studies with practical and supervised training in kindergartens. Twenty-seven subjects stressed:

Practice, practice, practice.

Practical experience! As a student, I feel I am learning from the experience in the kindergarten.

Experience in this area, which will empower me professionally, anyone can learn theory.

It is important for me to know the world of early childhood education; which only in the field and in the practical work I can get to know and learn.

Their pedagogic coordinator also strengthened these statements quoting their comments to her as "I have learned enough theory". Two indicated that they came with no expectations.

Only Few (five) students also recognized the importance of theoretical enhancement:

It is important to know the theories relating to early childhood education, to know how to build working programs in all aspects of children's development, and know how to work based on theory and tailored work programs for kindergarten children. 
I would like to study child psychology, building an accurate daily routine, how to get content across, how to develop children to the maximum and bring them to fulfillment and excellence.

It is important for me to recognize the first signs of developmental delay of children in order to give immediate and adequate treatment.

The more knowledge I accumulate I will become a more professional and creative educator.

One subject came with no expectations of the program:

I came with no expectations from school, I started from scratch.

A different voice came from one student who claimed that the program does not assist her in connecting between theory and practical needs at the kindergarten:

What is important to me is how educational issues are transferred in a manner that is correct and adjusted to age. I feel certain courses fail to convey the material in a form suitable to kindergarten. It would be preferable if the courses related to the holidays, identity, Bibles, etc., would be related to the kindergarten and to the way, they are conveyed to children. Another student presented an opposite opinion:

I will note that there are many things taught in theory that are truly reflected in the field, for example, what scholars and savvy have to say on the matter, stages of development, what the child needs, what is the evolution that matches each age, movement, singing and drama. Almost everything we have learned in the program had to do with the kindergarten.

The students' claim regarding the need to focus primarily on practical learning is consistent with the approach. This approach is similar to that described by Knowles claiming that the adult learner focus on practical implication rather than theory.

In summary, the findings reinforce the necessity to re-design the current training programs, both the theoretical courses and the practical work, and redefine the relationships between the domains and time allocation to each area. In addition, it is important to discuss the perception/approach that emphasizes the apprenticeship approach versus the theoretical learning approach and finding the proper combination between the two approaches while reflecting the students' own perceptions about learning to become kindergarten teacher.

\section{Discussion and Conclusions}

Mobility between jobs, changing profession and the need to form a new professional identity are currently common [3]. This study investigated the underlining motives of female academics that chose to study early childhood education as their second career. We found that electing early childhood teaching as second career, required the students to re-evaluate their professional future, this time by listening to their inner voice, their personalprofessional aspirations, sense of purpose and commitment, which are beyond oneself and reward.

It is apparent that the students comprehend the new career as a vocation rather than just a new profession. Profession is considered as a paid occupation, which includes formal and ongoing training for making a living. While vocation is defined as a deep sense of calling to a specific job as a provider of services rather than a salary, a sense of equivalence and being valuable that requires deep commitment with strong feelings of suitability for a particular career or occupation [3, 4]. Nevertheless, alongside intrinsic motives, there may be a degree of overlap between profession and vocation, that is to say one cannot assume that salary is not important [9]. The two terms are attributed to the type of work but only one of them emphasizes dedication and sense of mission. According to this view, the teaching profession is not only considered a job, but a commitment to serve others beyond yourself and wages [1]

The inner debates and the processes the students went through followed the four steps described previously in the transition theory [6], which have a reciprocal influence during a career change, namely:

Context: Choosing a second career stems mostly from a lack of interest or satisfaction in their current job and the fact that they became mothers. Motherhood exposed them to the existing education system, increased the sensitivity to the importance of the education provided to the next generation. This in turn sharpened their vigilance to the importance of early childhood education. Motherhood refined their criticism of the existing system and strengthened their belief in their capabilities to modify and improve the education system [12]. Believing in the need for quality human resource was one of the turning points in their electing preschool teaching.

Supporting figures: During the processes of recognizing their need for a change and its implementation, the students felt lonely. Each needed the support of another person. Hence, most of them mentioned a specific person who helped them overcome the difficulties along the way, to deal with the criticism of the surrounding relatives or friends and overcoming the social and economic perceptions. 
Motivation: All subjects reported personal motivation, the need for realization and satisfaction (see also: [3]), self-fulfillment and balance between work and satisfaction, or as Buijs [4] calls it, destiny or mission, derived of an "inner voice" - vocation.

Strategy: Unlike the first career choice, often made out of desire for status, prestige, or a parents' persuasion and without deep knowledge about work characteristics, the decision to switch careers is taken after a more thorough process that requires a process of insight and in-depth and courageous introspection of individual needs.

Academics, who choose teaching as a second career, bring with them a wealth of experience and extensive knowledge from their current field of expertise. However, our findings reveal that most of the students during the initial stages of their learning were unable to identify the advantage points of their prior knowledge and experience as potential factors to be implemented within the new profession. We found that their perceptions about preschool education were intuitive, expressing their educational desires aiming toward gaining practical tools. One of their pedagogic coordinators described it as "wisdom of maternal pedagogy". Similarly to previous studies, only few were able to attach their previous knowledge, skills and abilities to the new profession [22, 23].

The pedagogic coordinator claimed that she was able to help the students find within themselves their accumulated knowledge and experience, and to use it as a source of empowerment. However, such an activity was not part of the program's rationale but rather a very good personal initiative by the coordinator. When designing future education program for this population we suggest embedding specific goal and facilitate the process of figuring out how to turn previous personal knowledge, skills and experience into a valuable resource in the new field. This process should result in their empowerment as they gradually understand and articulate their contribution. This is in agreement with Arthur [7] that advocates that experience and skills should be used as "cross-boundary" assets not limited to a workplace or a specific job. Moreover, those who study towards a second career do so willingly; will learn what is relevant to them and their interests, from a desire to take responsibility for their decisions. They will drop out if the school does not satisfy them [10]. Therefore, it is important to adapt and structure the training programs for this population rather than just settle for programs geared towards undergraduate students. This process may, hopefully also lead to a new understanding of what they also need to acquire (that will be discussed next).

The findings show that the students expect practical-apprenticeship learning and only a small number seek theoretical expansion as a basis for specialization. They expect an increase in guided practical work which includes, among other things, an extended stay in the kindergarten, practical learning of work methods associated with management (such as dealing with parents, daily routine, learning content and behavior, etc.), similarly to what was previously described by others [24]. This expectation is apparently due to the significant professional change and out of the belief that practical problem solving experience will prepare better towards the reality they will meet as kindergarten teachers.

However, in our opinion, a practical approach is not sufficient to establish a good program. Such a program should emphasize "objective" theoretical learning. As noted by Plato: it is important for one to understand that the knowledge gained is a mix between beliefs collected and "truth", and should be exposed beyond his own beliefs to theories, concepts and approaches from different directions and other people. These can include additional teaching approaches, in order to build a rich and reliable knowledge base. Hence, the question is how to enthuse the importance of theoretical learning, as a foundation for understanding kindergarten work. While constructing a personalized program for such students, it is important to address their expectations but also focus on what they do not yet realize as important, the theoretical genres derived from daily issues of kindergarten routine. This goal can be achieved by applying the PBL1 (problem-Based learning) approach or similar ones, given that they will aim at knowledgeable discussions relating to events in the kindergarten with relation to theory, contributing together to insight and understanding. Such a process requires the construction of a comprehensive, flexible program, containing both the transfer of knowledge between different contexts, taking into account the framework in which the students' professional resources are properly used and learning takes place. Through this process, we assume students will build a comprehensive knowledge base relevant to the area of specialization, meets their expectations and links practice to theory.

For establishing a successful program, we recommend the following steps to be applied:

- Preparation meetings: To invite the applicants prior to their formal enrollment - interview them, acknowledge their motivation and prior experience, and describe the characteristics and qualities of the program including an open discussion concerning the importance of bringing themselves and their experiences, as well as learning various aspects of the professional - practical and theoretical. These meetings can become preparation for the faculty too to get to know these students' and their former skills that may be relevant. 
- Encourage participation in College events such as open days. Such events are excellent opportunities to allow those interested to acknowledge the process they will go through like attend classes, meet and talk with students and teachers, and visit the kindergartens and watch the work in progress.

- Initiate one on one meetings - during the studies be open to receiving feedback as well as providing formative feedback, and discuss issues that concern the specific student in search of professional and emotional response. The encounter with these students can become a unique opportunity to bring in new perspectives from different fields, from fresh eyes that have various expertise.

- Build a designated curriculum: Allocate time for mapping previous knowledge and background of the candidates, accumulated experience and skills in order to integrate them into the curriculum as a contributing and empowering resource.

- Implement, critical and reflective thinking, that would allow a combination of previous and acquired knowledge to be used. Such a process will encourage the students to respond to the new reality reflectively while adapting to a changing environment. This will allow examination of teaching strategies, improving learning and classroom management [23].

- It is important to consistently document the events in the kindergarten as a basis for raising practical questions to be discussed in class, in order to broaden the discussion and learning from theory and practice, while presenting consistent solutions with ramifications for the short and long term.

- It is recommended to hold an online discussion platform where students raise questions and issues that encourage an open professional discussion during school years and after graduation.

In conclusion, we found that students that choose teaching as a second career bring with them important knowledge, experience, skills and maturity that are valuable assets that can contribute greatly to the education process and field. It is therefore important to modify the programs dedicated to this population and recruit quality teaching personnel in order to assist the students in the process of developing their professional identity, empower them and enrich the education system with quality professionals that can use their expertise, and are open to true learning.

\section{References}

[1] Rafael, T., Teaching as a vocation. Psychiatry and Biological Processes, 2007. 70(3): p. 229-237.

[2] Mayotte, G.A., Stepping-stones to success: Previously developed career competencies and their benefits to career switchers transitioning to teaching. Teaching and Teacher Education, 2003. 19(7): p. 681-695.

[3] Lee, D., Changing course: Reflections of second career teachers. Current Issues in Education, 2011. 14(2): p. 118.

[4] Buijs, J.A., Teaching: Profession or Vocation? Catholic Education. Journal of Inquiry and Practice, 2005. 8 (3): p. 326-345.

[5] Richardson, P.W. and H. Watt, I've decided to become a teacher: Influences on career change. Teaching and Teacher Education, 2005. 21,(5): p. 475-489.

[6] Schlossberg, N., E. Waters, and J. Goodman, Counseling adults in transmission: Linking practice with theory. 2nd Ed ed. 1995, New York: Springer.

[7] Arthur, M.B., The boundaryless career: A new perspective for organizational inquiry. Journal of Organizational behavior, 1994. 15: p. 295-306.

[8] Arthur, M.B. and D.M. Rousseau, The boundaryless career: A new employment principle for a new organizational era. 1996, New York: Oxford University Press.

[9] Arthur, M.B., K. Inkson, and J. Pringle, The new careers: Individual action and economic change. 1999, CA: Sage: Thousand Oaks.

[10] Brindley, R. and A. Parker, Teachers and teaching: Theory and practice. Database, 2010. 16(5): p. 577-594.

[11] Castro, A.J. and M. Baumel, Why now? Factors associated with choosing teaching as a second career and their implications for teacher education programs. Teacher Education Quarterly, 2009. 36 (3): p. 113-126.

[12] Knowles, M.S., F.E. Holton, and A.R. Swanson, The adult learner the definitive classic in adult education and human resource development. 1989, Houston, Texas Gulf Publishing Comp.

[13] Schuetze, H., Lifelong learning and the learning society: From concept to policy to practice?, in Building stronger communities: Research informing policy and practice L. Doyle, et al., Editors. 2008, NIACE: Leicester, UK. p. 21-34.

[14] Creswell, J.W., Qualitative, quantitative, and mixed methods approaches 3rd Ed ed. 2009, California: Sage Publications, Inc.

[15] Moustakas, C., Phenomenological research methods. 1994, Thousand Oaks: Sage.

[16] Spradley, J., The ethnographic interview. 1979, New York: Holt: Rinehart \& Winston.

[17] Charon, J.M., Symbolic interactionism. 5th Ed. ed. 1995, Upper Saddle River: Prentice Hall. 
[18] Patton, M., Qualitative evaluation and research methods 2nd Ed ed. 1990, Newbury Park: Sage.

[19] Strauss, A. and J. Corbin, Basic of qualitative research: Grounded theory procedures and techniques. 1990, Newbury Park, CA: Sage

[20] Miles, M.B. and A.M. Huberman, eds. Qualitative data analysis. 2 ed. 1994, Sage: Thousand Oaks.

[21] Lincoln, Y. and A. Guba, Naturalistic inquiry. 1985, Newbury Park: sage.

[22] Resta, V., L. Huling, and N. Rainwater, Preparing second career teachers. Educational Leadership, 2001. 58 (8): p. 60-63.

[23] Jenkins, J.M. and M.L. Veal, Pre-service teachers' PCK development during peer coaching. Journal of Teaching Physical Education, 2002. 22(1): p. 49-68.

[24] Knowles, M.S., Andragogy in action. 1984, San Francisco: Jossey Bass. 